what services are offered to meet which needs; communicating regularly with referrers, and providing education or training to support referrers to improve their ability to meet patient needs directly.

\section{REVIEW OF POTENTIAL GEOGRAPHICAL DISPARITIES IN ACCESS TO ANTI-FIBROTIC MEDICATION AND CLINIC- BASED SPECIALIST PALLIATIVE CARE FOR PATIENTS WITH IDIOPATHIC PULMONARY FIBROSIS}

${ }^{1}$ Kym Wakefield, ${ }^{2}$ Evelyn Palmer, ${ }^{2}$ Claire Donaldson, ${ }^{1}$ Anne-Marie Bourke, ${ }^{2}$ lan Forrest. ${ }^{1}$ Marie Curie, UK; ${ }^{2}$ Newcastle upon Tyne Hospitals NHS Foundation Trust

10.1136/spcare-2019-mariecuriepalliativecare.49

Background Idiopathic pulmonary fibrosis (IPF) is a progressive interstitial lung disease of unknown origin (NICE, 2013). Disease-modifying anti-fibrotics are restricted to patients who meet specific criteria and are prescribed by regional IPF centres (NICE, 2016; NICE, 2018). Patients should be offered best supportive care from diagnosis (NICE, 2013). In January 2016 specialist palliative care (SPC) support was embedded in a regional IPF clinic. Initial service review (Kavanagh, 2017) suggested potential geographical disparities in access to both anti fibrotics and clinic-based SPC.

Aim To repeat the 2016 review to assess whether geographical disparities have changed over time.

Methods The sex, age and postcode of all patients with known IPF prescribed anti-fibrotics or seen by clinic-based SPC between January 2016 and April 2019 were collected retrospectively and geographically plotted. Chi squared goodness of fit was used to calculate statistical significance.

Results 398 patients were started on anti-fibrotics (male:female 330:68, mean age 74.7). Geographical plotting shows significant variation by region $(\mathrm{P}<0.01)$ ranging from 6.1 to 16.2 per 100,000 population, with comparatively low numbers of patients from Cumbria and North Durham (See figure 1). 80 patients were seen by SPC (male:female 65:15, mean age 74.9). Again, geographical plotting shows significant variation by region $(\mathrm{P}<0.02)$ ranging from 0.9 to 4.5 per 100,000 population, with a higher proportion of patients from NewcastleGateshead (See figure 2).

Discussion Geographical distribution of patients seen by clinicbased SPC appears to have changed little since 2016, with

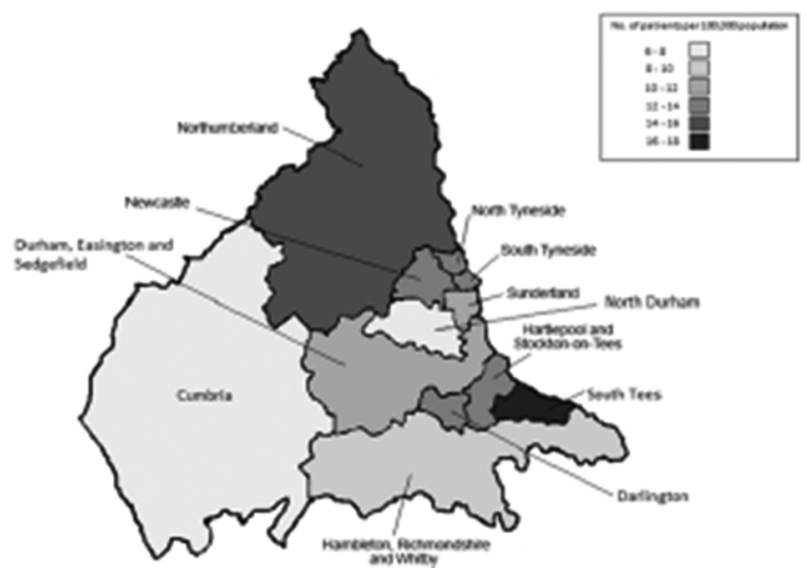

Abstract 49 Figure 1 Geographical distribution of patients started on antifibrotics Jan 2016 - Apr 2019

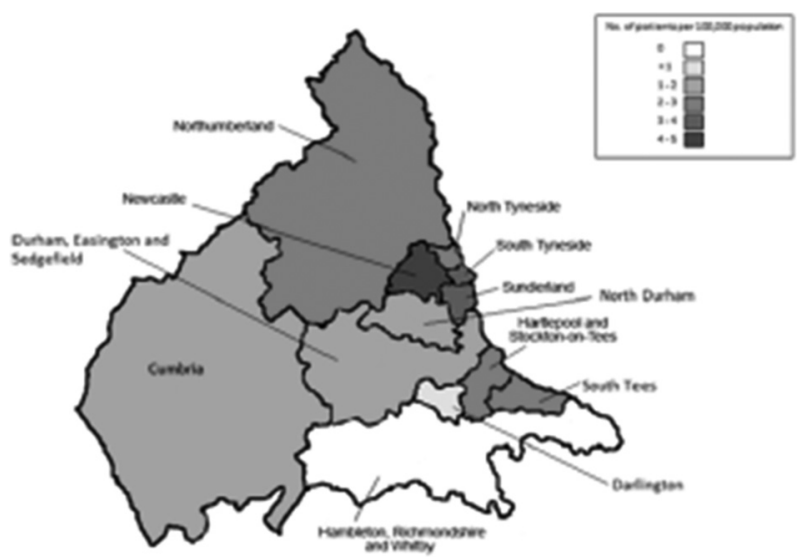

Abstract 49 Figure 2 Geographical distribution of patients reviewed by SPC in ILD clinic Jan 2016 - Apr 2019

clear centralisation to Newcastle-Gateshead. Speculatively, reasons for this could include travel distances and local palliative care provision. Geographical disparity in antifibrotic prescription is more difficult to account for and requires further investigation.

\section{REFERENCES}

1. National Institute for Health Care and Excellence (NICE). (2013) Idiopathic Pulmonary Fibrosis in Adults (CG163) [online]. https://www.nice.org.uk/guidance/cg163. Accessed 04/07/2019.

2. National Institute for Health Care and Excellence (NICE). (2016) Nintedanib for Treating Idiopathic Pulmonary Fibrosis (Technology Appraisal Guidance TA379) [online]. https://www.nice.org.uk/guidance/ta379. Accessed 04/07/2019.

3. National Institute for Health Care and Excellence (NICE). (2018) Pirfenidone for Treating Idiopathic Pulmonary Fibrosis (Technology Appraisal Guidance TA504) [online]. https://www.nice.org.uk/guidance/ta504/chapter/1-Recommendations. Accessed 04/07/2019.

4. Kavanagh $E$, et al. Integration of specialist palliative care into a tertiary nonmalignant service: evaluation of potential geographical disparity. BMJ Supportive \& Palliative Care 2017;7(Suppl 1):A33-A34.

\section{Systematic Reviews}

\section{FAMILY-CENTRED CARE IN HOSPICES: WHAT ABOUT THE CHILDREN?}

Steve Marshall, Richard Harding, Katherine Bristowe, Rachel Fearnley. King's College London, UK

\subsection{6/spcare-2019-mariecuriepalliativecare.50}

Palliative care professes to take a family-centred approach to patient care. ${ }^{1}$ However, children under 18 may not feel included when a parent is being cared for in a hospice. ${ }^{2}$ A systematic literature review of PsychINFO, Medline, Embase, Scopus and Web of Science was conducted, with no restriction on publication date. Nineteen studies met the inclusion criteria, all reporting primary data from children under 18 , whose parent has a life-limiting illness.

Findings from the review reveal that:

- Children and young people often feel excluded when a parent is dying.

- Communication about prognosis does not routinely happen with children.

- For children, the terminal period is generally more stressful than after the death. 
- There are discrepancies between the support children would like from professionals and

- The support they typically receive.

Recommendations highlighted by the review:

- Regular training for all hospice staff in relation to working with children - including recognition of how parental illness may affect children, the importance of communication, and children's understanding of death at different ages.

- Consideration of how children can be more routinely involved, for example inclusion in family meetings.

- Encouraging staff to explore patients' wishes and feelings in relation to their children.

- Consideration of whether the hospice environment is 'childfriendly'.

- Flexibility around working hours - children are often 'invisible' and visit parents in the evening and at weekends.

- Consideration of creative methods of including children, perhaps by using technology.

Hospices are encouraged to consider these recommendations and promote a model of family-centred care which includes children under 18 .

\section{THE UNMET HEALTH AND SOCIAL CARE NEEDS OF OLDER CAREGIVERS: A SYSTEMATIC REVIEW}

${ }^{1}$ Adeel Khan, ${ }^{2}$ Alisha Newman*, ${ }^{3}$ Mala Mann, ${ }^{4}$ Annmarie Nelson. ${ }^{1}$ School of Medicine, Cardiff University, UK; ${ }^{2}$ Marie Curie Palliative Care Research Centre, Cardiff, UK; ${ }^{3}$ Wales Cancer Research Centre, Cardiff University, UK; ${ }^{4}$ Specialist Unit for Review Evidence (SURE), Cardiff University, UK

10.1136/spcare-2019-mariecuriepalliativecare.51

Background There has been rapid growth in older caregivers (OCs) age $65+$ in the UK. ${ }^{1}{ }^{2} 3$ Playing a fundamental role in the life of their care-recipient, ${ }^{4}{ }^{5}$ helping to sustain preferred place of care, with many delivering over 50 hours of weekly care $^{6}$. OCs may themselves have age and caring role associated health issues. ${ }^{7} 8$ Spending cuts mean fewer now qualify for support. ${ }^{9}$ Understanding the breadth and extent of OCs unmet needs can inform support to help OCs maintain their wellbeing and caring role.

Aim To identify and describe the unmet health and social care needs of caregivers aged $65+$ in the UK.

Methods A systematic search was undertaken across a wide range of databases and grey literature from inception to February 2018. Two reviewers undertook study selection, data extraction and quality assessment. Qualitative Metasummary was used to synthesise findings.

Results In total 10 of 4407 identified records satisfied the inclusion criteria. Eight unmet need domains were identified, many were interrelated and displayed interplay: psychosocial, service, informational, constancy of care, future care planning, physical health issues, reluctance to utilise services, and financial needs.

Conclusions The review has identified eight domains of unmet need that may impact on OCs wellbeing and ability to care. OCs are a heterogeneous group with wide-ranging support needs, hence personalised carer's needs assessments are vital. Services need to be accessible, flexible and sufficiently available. Service information should be actively promoted. An extensive research gap on the unmet needs of OCs has been exposed.
Systematic Review Registration: CRD42018086759.

\section{REFERENCES}

1. Carers Trust. (2017) Key facts about carers and the people they care for. (n.d.). Retrieved February 21, 2019, from https://carers.org/key-facts-about-carers-andpeople-they-care

2. Office for National Statistics. (2011) Census analysis: Unpaid care in England and Wales, 2011 and comparison with 2001. UK: Office for National Statistics.

3. Pickard L. A growing care gap? The supply of unpaid care for older people by their adult children in England to 2032. Ageing and Society 2013;35:96-123.

4. Tomasa L, Shirai Y. (2008) Aging and Transitions Project: Technical Report and White Paper. US: University Center of Excellence in Developmental Disabilities Education, Research and Service.

5. Ismail S, Thorlby R, Holder H. (2014) Focus On: Social care for older people. England: Nuffield Trust and the Health Foundation.

6. Carers UK and Age UK. (2015) Caring into later life: The growing pressure on older carers. UK: Carers UK.

7. The Princess Royal Trust for Carers. (2011) Always On Call, Always Concerned: A Survey of the Experiences of Older Carers. UK: The Princess Royal Trust for Carers.

8. Adelman RD, Tmanova LL, Delgado D, Dion S, Lachs MS. Caregiver burden: a clinical review. JAMA 2014:311(10):1052-1060.

9. Ismail S, Thorlby R, Holder H. (2014) Focus On: Social care for older people. England: Nuffield Trust and the Health Foundation.

\section{EXPERIENCES OF SUPPORTING NUTRITION AND HYDRATION FOR SOMEONE LIVING WITH DEMENTIA AT THE END-OF-LIFE: A SYSTEMATIC REVIEW OF QUALITATIVE EVIDENCE}

${ }^{1}$ Yolanda Barrado-Martin, 'Lee Hatter, 'Elizabeth L Sampson, ${ }^{1}$ Greta Rait, ${ }^{2}$ Jill Manthorpe, ${ }^{1}$ Christina Smith, ${ }^{1}$ Nathan Davies. 'University College London, UK; ${ }^{2}$ King's College London, UK

10.1136/spcare-2019-mariecuriepalliativecare.52

Background People living with dementia often face eating and drinking difficulties as life is ending. Family and friends find this emotionally challenging and professionals also struggle to provide information and support. The aim of this systematic review was to 1 ) explore the views of people with dementia and those involved in supporting eating and drinking for someone with dementia (paid and unpaid carers) at the end of life; and 2) explore views and experiences of artificial nutrition and hydration (ANH) for people with dementia.

Methods A systematic search was conducted in Medline, CINAHL, Embase and PsycINFO, for English-language qualitative studies published between 2000 and 2019, and forward and backward citation tracking. Studies were synthesised using narrative synthesis and thematic analysis methods.

Results 18 papers were included with six focussing on carers' and 13 on professionals' views. Professionals and carers reported on challenges associated with supporting nutrition and hydration and several strategies used to facilitate oral intake (i.e., modifying the environment and food provision). When ANH was considered, six main factors were identified as influencing decisions: 1) personal perceptions; 2) national context; 3) understanding of the natural dying process; 4) involvement of different parties (i.e., professionals in multidisciplinary teams, carers and the person living with dementia); 5) lack of information; and 6) prognosis.

Discussion Decisions around eating and drinking and the introduction of ANH require clear and respectful communication among all involved (including those living with dementia), as their personal/professional experiences, perceptions and knowledge impact on their behaviours and emotions. 